\title{
Curadoria digital: novos modelos de participação pública na descrição de conteúdos em instituições culturais ${ }^{1}$
}

\author{
Aquiles Alencar Brayner \\ British Library, London, England \\ abrayner@yahoo.com
}

DOI: https://doi.org/10.26512/rici.v11.n3.2018.10521

Recebido/Recibido/Received: 2018-06-05

Aceitado/Aceptado/Accepted: 2018-07-30

Resumo: Analisa a participação de usuários em atividades de descrição de conteúdos eletrônicos (folksonomia), discutindo estas práticas no contexto da curadoria digital, especialmente em referência ao modelo do ciclo de vida do objeto digital estabelecido pelo Digital Curation Centre (DCC). O modelo, embora outorgando um papel de relevância à comunidade de usuários, entende este grupo como formado exclusivamente por profissionais e pesquisadores familiarizados com a gestão dos acervos digitais. Esta concepção exclui a importância de todos os outros possíveis grupos de usuários que, não se enquadrando nas categorias descritas pelo modelo DCC, interagem com os acervos digitais de instituições memoriais disponibilizados em rede, outorgando-lhes novas categorias descritivas e múltiplas alternativas de uso.

Palavras-chave: folksonomia. indexação. instituições de memória. metadados. objeto digital.

\section{Curaduría digital: nuevos modelos de participación pública en la descripción de contenidos en instituciones culturales}

Resumen: El artículo analiza la participación de usuarios en actividades de descripción de contenidos electrónicos (folksonomía), discutiendo estas prácticas en el contexto de la curaduría digital, especialmente en referencia al modelo del ciclo de vida del objeto digital establecido por el Digital Curation Centre (DCC). El modelo, aunque otorgando un papel de relevancia a la comunidad de usuarios, entiende este grupo como formado exclusivamente por profesionales e investigadores familiarizados con la gestión de los acervos digitales. Esta concepción excluye la importancia de todos los demás posibles grupos de usuarios que, no se encuadran en las categorías descritas por el modelo DCC, interactúan con los acervos digitales de instituciones memorias disponibles en red, otorgándoles nuevas categorías descriptivas y múltiples alternativas de uso.

Palabras-clave: indización. objeto digital. folksonomía. instituciones de memoria. metadatos.

\section{Digital curatorship: new models of public participation in the description of contents in cultural} institutions

Abstract: This article analyses the participation of users in the description of electronic content (folksonomy), discussing these practices in the context of digital curation, especially about the lifecycle model for digital object suggested by the Digital Curation Center (DCC). The model, although ascribing relevance to the community of users, understands this group as formed exclusively by professionals and researchers familiar with the management of digital collections. This concept excludes the importance

\footnotetext{
1 Texto originado de palestra proferida no XI Workshop Internacional em Ciência da Informação, Faculdade de Ciência da Informação e Programa de Pós-graduação em Ciência da Informação da Universidade de Brasília. Brasília, 12-15 de setembro de 2016.
} 
of all other possible groups of users who, not falling within the categories described by the DCC model, interact with digital collections provided via Internet by memory institutions, offering to these collections new descriptive categories and multiple alternatives of use.

Keywords: digital object. folksonomy. indexing. memory institutions. metadata.

\section{Curadoria digital e participação comunitária segundo o modelo do Digital Curation Centre}

O número exponencial de dados e objetos digitais produzidos e disponibilizados por centros de pesquisa, órgãos governamentais e instituições culturais, vem abrindo espaço à curadoria digital enquanto campo proposto a definir novas políticas de acesso e práticas para a disseminação e reutilização de acervos eletrônicos. O termo, utilizado pela primeira vez em 2001, no evento Digital Curation: digital archives, libraries and e-Science seminar, promovido pela Digital Research Coalition em Londres, apontava para a necessidade de se fomentar discussões e determinar atividades de ação conjunta para a gestão de acervos digitais, no intuito de "compartilhar experiências práticas de curadoria digital no setor de bibliotecas digitais, arquivos e ciências eletrônicas" (DIGITAL PRESERVATION COALITION, 2001, tradução nossa). Desde então, a elaboração de conceitos teóricos, criação de planos estratégicos e aplicação de modelos operacionais no campo da curadoria digital vêm se estabelecendo de forma cada vez mais ampla e consistente para o gerenciamento, acesso e utilização dos acervos e dados eletrônicos.

Em 2004 se inaugura o Digital Curation Centre (DCC), com o objetivo de formular recomendações e estabelecer normas e políticas de gestão para acervos digitais no Reino Unido, promovendo, desta forma, ações mais sistematizadas a nível nacional, garantidoras do "gerenciamento, preservação e agregação de valor a dados científicos digitais durante o seu ciclo de vida" (DIGITAL CURATION CENTRE, tradução e grifo nossos). Como especificado em sua definição, o DCC foi criado para atender especificamente as necessidades de gestão de dados científicos, o que não diminui a validade de suas postulações e modelos operacionais para outros órgãos que não somente aqueles voltados à pesquisa acadêmica.

Uma das maiores contribuições do DCC na área de acervos eletrônicos foi a formulação de um esquema gráfico (figura 1) indicando as ações necessárias para o gerenciamento e preservação, a longo prazo, de dados e objetos digitais, configurado por um caráter cíclico, interdependente e ininterrupto: 
Figura 1: Ciclo de vida do objeto digital

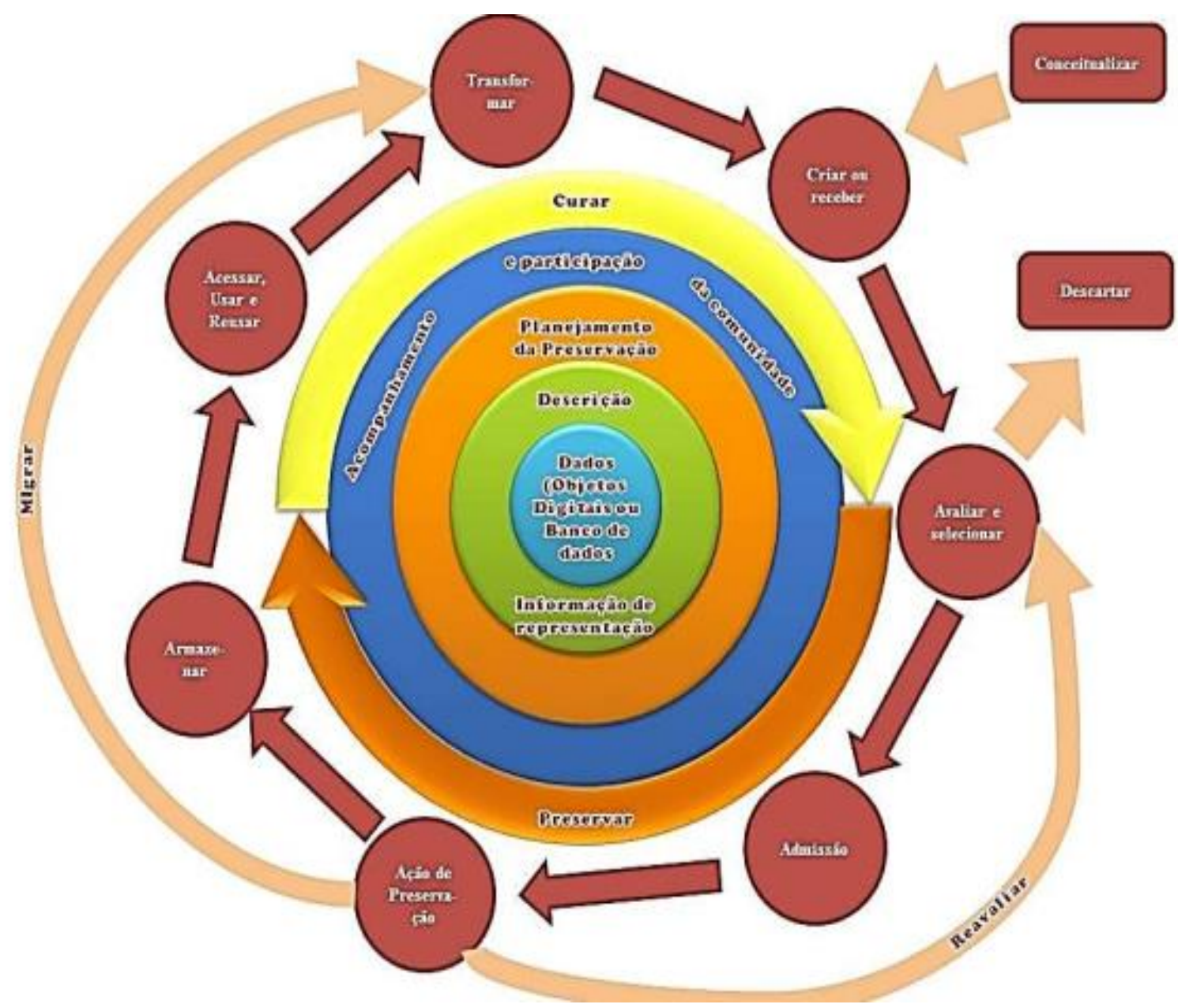

Fonte: https://curadoriadigitalblog.wordpress.com/2015/11/13/ciclo-de-vida-da-curadoria-digital/

Este esquema (figura 1), representado a partir de uma estrutura recursiva, demonstra que a gestão dos objetos e dados digitais é um processo que demanda um acompanhamento constante do desenvolvimento tecnológico e revisão das políticas de gestão digital, de modo a garantir a acessibilidade e a utilização dos conteúdos eletrônicos no futuro. No centro da estrutura se coloca o objeto e dados digitais, em torno dos quais gravitam as ações de curadoria. Quanto mais próximas ao núcleo do gráfico, mais importantes serão as medidas a serem tomadas para garantir uma gestão satisfatória dos acervos eletrônicos. Nesta perspectiva, as ações em curadoria digital estariam dividas em três etapas, segundo a relevância de cada uma delas no ciclo proposto:

\section{Ações completas ou essenciais:}

a. Descrição e informação de representação 

b. Planejamento da preservação
c. Acompanhamento e participação da comunidade
d. Curar e Preservar

\section{Ações sequenciais:}
a. Conceitualizar
b. Criar ou receber
c. Avaliar e selecionar
d. Admissão
e. Ação de preservação
f. Armazenar
g. Acessar, usar e reusar
h. Transformar

\section{Ações ocasionais:}
a. Descarte
b. Reavaliação

De maneira mais genérica, o que se observa na proposta curatorial sugerida pelo DCC é uma sequência de processos imprescindíveis que vão desde o planejamento inicial para a formação do acervo eletrônico (ações essenciais), passando, posteriormente, para a fase da implementação de sistemas e políticas de gestão do acervo (ações sequenciais), para, eventualmente, determinar, conforme necessário, a reavaliação e possível descarte do objeto digital ou base de dado do repositório institucional (ações ocasionais). O que nos chama a atenção na esquematização do ciclo de vida dos conteúdos digitais elaborado pelo DCC é a ausência de uma discussão mais centrada no papel dos usuários, especialmente nos processos de seleção, descrição e possibilidades de uso dos objetos eletrônicos e as informações a eles pertinentes. Isto se explica, em parte, pelo fato de o modelo ter sido inicialmente pensado para a gestão de dados científicos, deixando de considerar as peculiaridades informacionais e a heterogeneidade dos grupos de usuários que acessam e utilizam objetos eletrônicos em contextos que não o da pesquisa, como é o caso, por exemplo, dos consumidores de acervos culturais.

A única referência neste modelo que indica, ainda que de maneira não totalmente explícita, a participação pública nos processos de seleção, enriquecimento de dados e alternativas de reavaliação e reuso dos objetos digitais, aparece mencionada na atividade de "acompanhamento e participação da comunidade," que compõe as ações essenciais a serem desenvolvidas pela curadoria digital. O termo "comunidade," tal como empregado no gráfico do DCC, refere-se de modo mais específico a determinados grupos que desenvolvem 
"atividades comunitárias apropriadas" com participação ativa no "desenvolvimento de padrões compartilhados, ferramentas e software adequados" (HIGGINS, 2008, p. 137, tradução nossa), tais como os profissionais da Ciência da Informação que trabalham com a gestão e preservação de dados e objetos digitais, bem como as equipes técnicas mais diretamente voltadas ao campo da tecnologia da informação, responsáveis pelo desenvolvimento dos suportes de arquivamento de objetos eletrônicos e aprimoramento de plataformas de acesso a estes conteúdos. Esta definição não contempla, portanto, comunidades de usuários que, demonstrando necessidades informacionais distintas e cada vez mais complexas, possam definir os objetos digitais de maneira a enriquecer os dados fornecidos por bibliotecas, arquivos e museus, contribuindo de forma efetiva na descrição de seus acervos.

Alguns dos autores que discorrem mais especificamente sobre a atividade de observação e participação da comunidade no ciclo de vida do objeto digital, destacam que o trabalho de curadoria digital envolve uma constante reavaliação e inclusão de dados informacionais através da "agregação de valor à base de dados e objetos digitais, tal como a inserção de novos metadados ou anotações adicionais de modo a favorecer a reutilização destes conteúdos" (OLIVER; HARVEY, 2016, p. 8, grifo dos autores, tradução nossa). A agregação de valor aos objetos eletrônicos aparece enquanto tarefa delegada principalmente aos curadores digitais, que seriam responsáveis pela "criação de metadados e anotações para garantir que os objetos digitais possam ser reutilizados" (OLIVER; HARVEY, 2016, p. 58, tradução nossa). Em relação às anotações geradas por terceiros, considerando-se mais especificamente os usuários que acessam dados científicos, como acadêmicos e pesquisadores, os autores postulam que estes "possuam alguma familiaridade com a curadoria digital garantindo que as anotações que produzam sejam descritas e documentadas de modo a serem entendidas por outros usuários" (OLIVER; HARVEY, 2016, p. 61, tradução nossa). Neste contexto, como podemos observar, a participação pública no processo de enriquecimento descritivo de dados sobre os objetos digitais estaria relegada à profissionais qualificados que tenham, de alguma forma, um conhecimento prévio do processo de curadoria digital de modo a oferecer uma contribuição mais relevante à gestão de acervos eletrônicos.

\section{Folksonomia em instituições de memória}

A conceitualização do termo "comunidade de usuários" descrita no modelo oferecido pelo DCC, desenvolvido mais particularmente no contexto da gestão de objetos e dados científicos, se problematiza quando o nosso foco de investigação passa a ser o usuário que acessa catálogos e objetos digitais de bibliotecas, arquivos e museus. Este usuário, sem 
preencher necessariamente um perfil definido enquanto pesquisador ou acadêmico e, muito provavelmente, desprovido de uma compreensão mais abrangente do trabalho envolvido na prática de curadoria de dados e conteúdos eletrônicos, exerce uma função essencial no processo de descrição dos objetos digitais culturais.

Um número crescente de instituições de memória cultural tem promovido a participação pública para o enriquecimento dos dados que figuram em seus catálogos online de modo a favorecer "a descoberta da informação para usuários, agora e no futuro, que possuam necessidades informacionais completamente distintas da maneira em que a informação foi originalmente criada e descrita, e quem a procura, portanto, de maneiras diferentes" (RAY, 2009, p. 361, tradução nossa). Tendo em vista as múltiplas possibilidades de recuperação de dados digitais provenientes de instituições de memória cultural e as várias formas de acesso a estes conteúdos que se encontram disseminados por meio da Internet, é evidente que o potencial das instituições culturais de servir a diferente grupos de usuários que não se enquadram no perfil daqueles que conhecem ou fazem comumente uso dos seus acervos, se amplia de uma maneira nunca antes experienciada. Isto faz com que equipamentos culturais de memória tenham que adequar a representação informacional de seus acervos de modo a se comunicar de maneira efetiva e direta com suas novas comunidades de usuários. Como afirma Viviane Reding (2005), referindo-se à situação específica das bibliotecas, estas

enfrentam desafios reais para lidar com a transição para a era digital. Para evitar se tornarem os dinossauros do futuro, elas precisam se adaptar, atrair novos e jovens usuários e desenvolver novos modelos de negócios. Isso implica mudanças profundas nas organizações, nas habilidades e às vezes em atitudes. (REDING, 2005, p. 7, tradução nossa)

Via de regra, as informações oferecidas em catálogos eletrônicos de bibliotecas replicam os registros bibliográficos criados para as fichas catalográficas físicas. Devido às suas dimensões padronizadas de $12,5 \mathrm{~cm} \times 7,5 \mathrm{~cm}$, estas fichas restringiam o espaço de descrição do dado bibliográfico, resultando, assim, na concisão das informações apresentadas. Com o advento dos catálogos eletrônicos, estas fichas caíram em desuso. ${ }^{2}$ Apesar disto, as regras de descrição e catalogação que nortearam os bibliotecários na elaboração das fichas catalográficas desde o século antepassado mantiveram-se praticamente inalteradas. A concisão generalizante antes exigida pelas normas catalográficas vem, conforme apontam alguns pesquisadores, perdendo relevância no contexto informacional da atualidade (ANTELMAN; LYNEMA; PACE, 2006).

\footnotetext{
${ }^{2}$ De acordo com a OCLC, a produção da última ficha catalográfica física, em 1 de outubro de 2015, se dá em decorrência da obsolescência deste formato pela adoção global de catálogos eletrônicos por bibliotecas à nível global (OCLC, 2015).
} 
De fato, os dados disponibilizados pelos catálogos de bibliotecas, normalmente apresentados de maneira uniformizada, resumida, pré-estabelecida e hierárquica, já não parecem responder, adequadamente, ao comportamento e necessidades informacionais do usuário contemporâneo, imerso numa cadeia incessante de produção e consumo de informação em meio eletrônico. ${ }^{3}$ Este modo secular e centralizador de tratar os registros tem servido, majoritariamente, enquanto modelo estrutural de ordenação e recuperação da informação que atende a um número restrito de profissionais iniciados em suas técnicas.

A Internet, e, mais especificamente, o espaço interativo proporcionado por ferramentas da Web 2.0, favorecem e estimulam um modelo participativo onde usuários estabelecem uma "organização cooperativa" da informação (LÉVY, 2014, p. 193), resultando em novas estruturas descritivas baseadas em elementos mais diversificados e, portanto, mais abrangentes, já que estas descrições não se norteiam por um modelo único e específico firmado por uma regra classificatória.

A hierarquização informacional que, por tanto tempo, definiu as práticas taxonômicas em bibliotecas, arquivos e museus, vai cedendo espaço para a adoção de uma estrutura mais distribuída e democrática na identificação e ordenamento de documentos, de modo a facilitar a recuperação, acesso e utilização deste conteúdo por diferentes comunidades. Levando-se em consideração que toda informação publicada na Web se encontra em um mesmo plano onde não há hierarquia absoluta de conteúdos, já que cada site é um agente de seleção, de bifurcação ou de hierarquização parcial, observamos que, longe de ser uma massa amorfa, a Web articula uma multiplicidade aberta de pontos de vista. Esta articulação é feita transversalmente, em rizoma, sem uma ordenação ou unificação informacional sobrejacente. É inconteste que este estado de coisas engendre certo nível de confusão. Este contexto exige que novos instrumentos de indexação e pesquisa sejam pensados, como podemos observar pela profusão de trabalhos atuais que discorrem sobre a cartografia dinâmica dos espaços de dados, os "agentes" inteligentes ou a filtragem cooperativa das informações (LÉVY, 2014, p. 162).

Uma das maiores vantagens dos catálogos eletrônicos é que, contrariamente às fichas catalográficas em papel, eles não estabelecem limites para o número de termos ou entradas a serem incluídos nos registros bibliográficos. Essa flexibilidade faz com que hoje seja possível adicionarmos cada vez mais informações para as descrições dos objetos digitais, facilitando, assim, a sua descoberta por um número maior de pessoas. É neste contexto que o emprego de técnicas folksonômicas ou modelos de "autoridades abertas" (PHILLIPS, 2014), como no caso

\footnotetext{
3 Para uma discussão mais detalhada sobre a gradual obsolescência dos sistemas de catalogação bibliográfica na era da informação eletrônica, consultar TENNANT (2002; 2004) e GONZALES (2014).
} 
dos tagueamentos ou etiquetagens, definidos enquanto "método colaborativo para organizar conteúdo pelas pessoas utilizando o idioma das pessoas" (ZAVERI; ATKEKAR, 2014, p. 149, tradução nossa), venha sendo cada vez mais adotado por instituições memoriais no intuito de promover alternativas de interação pública com seus acervos.

Ao favorecer novas interpretações aos objetos culturais por meio de atividades de etiquetagem, os usuários passam a ter uma participação mais ampla na inserção de dados em catálogos institucionais, auxiliando também outros usuários que compartilham seus vocabulários terminológicos a descobrirem os objetos, possibilitando-lhes, da mesma forma, novas alternativas de uso. Estas descrições públicas oferecem uma oportunidade única para que instituições de memória cultural possam trabalhar de forma coletiva e participatória com os seus usuários de modo a enriquecer, atualizar e complementar as taxonomias, vocabulários controlados e sistemas classificatórios que foram incialmente projetados e desenvolvidos pelas próprias bibliotecas para atender às suas necessidades no contexto de suas coleções físicas no século XIX. A vantagem do etiquetamento parte do pressuposto de que "os usuários possam organizar a informação de modo que estas, adaptando-se às necessidades daqueles, possam ser recuperadas em um momento futuro" (ANFINNSE; GHINEA; DE CESARE, 2011, p. 64), promovendo, da mesma forma, maior visibilidade aos acervos culturais graças ao enriquecimento da classificação oferecida originalmente aos objetos que as instituições albergam.

As classificações temáticas, indexações ou listas de cabeçalhos, quando aplicadas a obras que abordam assuntos complexos e/ou profusos, acabam por restringir, em vez de facilitar, a descoberta do próprio conteúdo, haja vista que a sua representação se encontra, muitas vezes, atrelada e restrita a uma categoria classificatória excludente, fundamentada sobre uma hierarquização que impossibilita novas variantes descritivas.

Analisando o caso específico de Grande Sertão: Veredas de João Guimarães Rosa, para citarmos aqui um exemplo concreto, observamos que a catalogação da obra tal qual a encontramos em bibliotecas, segue uma classificação pré-estabelecida enquanto parte de um gênero literário (romance), atribuída a uma produção dentro de uma espacialidade geográfica (literatura brasileira), periodicidade (Geração de 45) ou grupo de escritores (Modernistas), sem, no entanto, abarcar todos os outros temas que, embora não considerados enquanto assuntos centrais na categorização do romance, possuem uma importância fundamental para o seu entendimento. A complexidade dos elementos que fazem parte de Grande Sertão Veredas, sem adentrar aqui em uma consideração mais detalhada sobre os temas abordados no livro, sugere uma série de outras categorizações não expressas nos catálogos bibliográficos, 
e que, nem por isso deixam de ser relevantes para a descoberta da obra por outros usuários que não somente aqueles interessados em literatura.

O romance de João Guimarães Rosa pode ser classificado enquanto estudo antropológico, já que relata a experiência do sertanejo, da mesma forma que também se enquadraria na categoria de romance homoafetivo, visto que narra a relação e os sentimentos do protagonista Riobaldo pelo seu companheiro Diadorim. A obra poderia ainda ser concebida como reflexão teológica, considerando que a narrativa aporta observações sobre as relações entre o homem, Deus e o diabo. Toda essa amplitude de referências informacionais sobre um mesmo objeto, das quais mencionamos apenas algumas, estão excluídas na grande maioria dos catálogos bibliográficos na descrição do Grande Sertão: Veredas.

Para suprir estas deficiências presentes nos catálogos institucionais, muitas bibliotecas, arquivos e museus estão oferecendo opções em seus catálogos abertos para que os usuários cadastrados possam sugerir suas próprias considerações descritivas a partir do entendimento individual e/ou de grupo que se tenham sobre um determinado objeto. As técnicas de etiquetamento, apoiadas pelas ferramentas Web 2.0 que promovem a interação de usuários e acervos, oferecem múltiplos pontos de entradas para descrições da informação de maneira mais condizente com as suas inúmeras interpretações e possibilidades de uso. Afinal de contas, a questão enfrentada hoje pelas instituições de memória cultural não diz respeito somente à disponibilização de seus conteúdos na Internet, mas, principalmente, sobre o modo em que estas instituições passam a ter as suas regras classificatórias e taxonomias

questionadas por aqueles que têm estado tradicionalmente à margem da sociedade, não tendo representatividade nos acervos institucionais, e pelos nativos digitais que possuem uma concepção totalmente diferente sobre autoridade e autoria da informação (YAKEL, 2011, p. 97, tradução nossa).

Outras instituições, principalmente aquelas que, por falta de apoio técnico ou recursos financeiros, não estejam ainda abrindo espaço em seus catálogos para que usuários possam cooperar de maneira efetiva no etiquetamento de dados catalográficos, estão optando pelo uso de plataformas abertas para favorecer novos modelos de participação pública.

A plataforma Flickr é um desses exemplos. Adotada por um número crescente de instituições memoriais, o objetivo da plataforma é disponibilizar os objetos eletrônicos para usuários que não estejam habituados a visitar páginas Web ou a utilizar os catálogos de bibliotecas, arquivos e museus. Os conteúdos disponibilizados na plataforma Flickr são mais facilmente descobertos por usuários, já que, tanto os dados catalográficos oferecidos pelas instituições, quanto os etiquetamentos gerados pelo público são rastreados e posteriormente 
indexados por robôs que dão suporte às máquinas de busca, facilitando, assim, a recuperação da informação na Internet.

O projeto Flickr Commons, lançado em parceria com a Library of Congress (Estados Unidos), vem estabelecendo, desde então, projetos colaborativos voltados, exclusivamente, a instituições de memória cultural, tendo como objetivo "catalogar os acervos públicos de imagens, aumentar o acesso a coleções de imagens destes acervos e fornecer um caminho para a contribuição pública com informações e conhecimentos sobre o material disponibilizado" (FLICKR COMMONS, 2017, tradução nossa).

Desde o seu início, em 2004, o Flickr se tornou uma das plataformas abertas mais usadas para o compartilhamento de imagens via Internet e aplicativos para dispositivos móveis, contando com mais de 36 milhões de usuários cadastrados que podem adicionar etiquetas (tags) e fornecer comentários aos conteúdos disponibilizados, tais como links a outras plataformas e informações online referentes aos objetos acessados. Estas anotações públicas são repassadas às instituições detentoras do acervo digital, de modo que elas possam adicionar os dados gerados por usuários aos seus catálogos. Uma outra vantagem oferecida pela plataforma Flickr é o agrupamento, também realizado pelo público, dos conteúdos oriundos de diferentes instituições que tratem de um mesmo tema, auxiliando, desta forma, na organização dos vastos e cada vez mais integrados acervos disponibilizados por bibliotecas, arquivos e museus na Internet.

\section{Conclusão}

De acordo com o que foi discutido neste artigo, a participação colaborativa de usuários na descrição de informações disponibilizadas em catálogos de instituições memoriais vem se tornando uma prática corrente adotada por bibliotecas, arquivos e museus. O advento da Internet, principalmente as possibilidades que emergiram a partir do desenvolvimento e implementação de ferramentas Web 2.0, deram um novo ímpeto à disseminação e descrição da informação por parte do público que a utiliza, alterando de maneira significativa o modo com que as instituições memoriais apresentam os seus objetos. Este processo de interação pública com os acervos institucionais responde de maneira mais adequada aos comportamentos informacionais da atualidade onde

a profusão do fluxo de informações e a ausência de uma ordem global a priori não impedem que a coletividade ou as pessoas orientem-se por sua própria conta e construam hierarquias, seleções, estruturas. Desapareceram definitivamente as seleções, hierarquias e estruturas de conhecimento pretensamente válidas para todos e a qualquer tempo, ou seja, o universal totalizante... A rede é, antes de tudo, um instrumento de comunicação entre 
pessoas, um laço virtual em que as comunidades auxiliam seus membros a aprender o que querem saber (LÉVY, 1998).

O etiquetamento, realizado por meio da participação interativa do usuário na descrição da informação se apresenta, neste sentido, como uma alternativa viável para o enriquecimento informacional dos catálogos institucionais, estabelecendo novas relações entre objetos e áreas do conhecimento. Cabe à curadoria digital o papel de mediar a relação entre a informação, o objeto eletrônico e o usuário, objetivando abrir novos canais e possibilidades de interação entre estes três elementos.

Entretanto, tem-se observado uma tendência por parte de pesquisadores e instituições de fomento em discutir a sustentabilidade do objeto digital sem se considerar, na maioria das vezes, a participação dos usuários nos processos de seleção, descrição e uso destes objetos, centrando, em contrapartida, forte atenção na preservação dos mesmos.

No caso específico do modelo oferecido pelo DCC, conforme brevemente discutido no início deste artigo, aponta-se ainda nas primeiras fases de planejamento das coleções digitais, a necessidade de se trabalhar, conjuntamente, com a comunidade que faz uso deste acervo, de modo a enriquecer os seus metadados. O conceito de comunidade utilizado pelo DCC parece, no entanto, restringir-se a usuários previamente identificados que demonstrem familiaridade com o trabalho de gestão de acervos eletrônicos. Esta conceituação, já que estabelecida no âmbito específico da curadoria de dados e objetos científicos, não responde, satisfatoriamente, às demandas informacionais com as quais se deparam as instituições memoriais na atualidade.

Para instituições que atendem a uma gama diversificada de público por meio da oferta dos seus acervos em rede, se faz impossível determinar a priori quais os usuários que estariam mais aptos a contribuir de maneira a enriquecer a descrição dos acervos culturais. Assim sendo, se faz necessário reavaliar o esquema de curadoria digital elaborado pelo DCC, considerando-se de maneira mais detalhada a relevância dos diferentes grupos de usuários na descrição dos objetos e dados digitais. Em última instância, o foco da curadoria digital, quando entendida como contribuição ao trabalho dos bibliotecários, arquivistas e museólogos, não deve ater-se ao objeto eletrônico como um componente isolado, mas sim entendê-lo numa relação interativa com os seus possíveis usuários, de modo a promover uma maior descoberta, acesso e utilização dos acervos disponibilizados em rede. 


\section{Referências}

ANFINSEN, S; GHINEA, G.; DE CESARE, S. Web 2.0 and folksonomies in a library context. International journal of information management: the journal for information professionals, Amsterdam, v. 31, n. 1, p. 63-70, February 2011. Disponível em:

<https://dl.acm.org/citation.cfm?id=2297848>. Acesso em: 15 set. 2017.

ANTELMAN, K.; LYNEMA, E.; PACE, A. Towards a twenty-first century catalog. Information technologies and libraries, Ann Arbor (MI), v. 25, n. 3, p. 128-139, 2006. Disponível em: <https://ejournals.bc.edu/ojs/index.php/ital/article/view/3342>. Acesso em: 22 set. 2017.

DIGITAL CURATION CENTRE. What is digital curation? Disponível em:

<http://www.dcc.ac.uk/digital-curation/what-digital-curation>. Acesso em: 26 set. 2017.

DIGITAL PRESERVATION COALITION. Digital curation: digital archives, libraries and e-science. London, 19th October 2001. Disponível em http: <www.dpconline.org/events/pastevents/digital-curation>. Acesso em: 11 set. 2017.

FLICKR COMMONS. Help us catalogue the world's public photo archives. Disponível em <https://www.flickr.com/commons>. Acesso em: 6 out. 2017.

GONZALES, B. M. Linking Libraries to the Web: Linked Data and the Future of the Bibliographic Record. Information technology and libraries, Ann Arbor (MI), v. 33, n. 4, p. 10-22, 2014. Disponível em: <https://ejournals.bc.edu/ojs/index.php/ital/article/view/5631>. Acesso em: 10 out. 2017.

HIGGINS, S. The DCC curation lifecycle model. The international journal of digital curation, Edinburgh, v. 3, n. 1, p. 134-140, 2008. Disponível em: <http://www.ijdc.net/index.php/ijdc/article/viewFile/69/48> Acesso em 25 set. 2017.

LÉVY, P. Um sistema autoregulador: a Internet tem sido capaz de criar mecanismos próprios de controle das informações. Folha de São Paulo, São Paulo, 12 abr. 1998. Disponível em: <http://www1.folha.uol.com.br/fsp/mais/fs12049804.htm>. Acesso em: 11 set. 2017.

LÉVY, P. Cibercultura. São Paulo: Editora 34, 2014.

ONLINE COMPUTER LIBRARY CENTER (OCLC). OCLC prints last library catalog cards. Dublin (Ohio), 1 October 2015. Disponível em:

<https://www.oclc.org/en/news/releases/2015/201529dublin.html>. Acesso em: 22 set. 2017.

OLIVER, G.; HARVEY, R. Digital curation. London: Facet Publishing, 2016.

PHILLIPS, L. B. The role of open authority in a collaborative web. In: RIDGE, M. (Ed.).

Crowdsourcing our cultural heritage. Surrey: Ashgate, 2014. p. 247-267. 
RAY, J. Sharks, digital curation, and the education of information professionals. Museum management and curatorship, London, v. 24, n. 4, p. 357-368, Dec. 2009. Disponível em: <http://www.tandfonline.com/doi/abs/10.1080/09647770903314720 . Acesso em: 20 set. 2017.

REDING. V. The role of libraries in the information society. In: CONFERENCE OF EUROPEAN NATIONAL LIBRARIANS, Luxembourg, 29 Sept. 2005. Disponível em:

<http://europa.eu/rapid/press-release_SPEECH-05-566_en.pdf>. Acesso em: 20 set. 2017.

TENNANT, R. MARC must die. Library journal, Nova lorque, v. 127, n. 17, p. 26-28, Oct. 2002. Disponível em: <http://lj.libraryjournal.com/2002/10/ljarchives/marc-must-die/\#_>. Acesso em: 27 set. 2017.

TENNANT, R. A bibliographic metadata infrastructure for the twenty-first century. Library Hi Tech, v. 22, n. 2, p.175-181, 2004. Disponível em: <http://www.emeraldinsight.com/doi/full/10.1108/07378830410524602>. Acesso em: 27 set. 2017.

YAKEL, E. Balancing archival authority with encouraging authentic voices to engage with records. In: THEIMER, K. (Ed.). A different kind of Web: new connections between archives and our users. Chicago: Society of American Archivists, 2011. p. 75-101.

ZAVERI, P.; ATKEKAR, M. Collaborative tagging in digital libraries. International journal information dissemination and technology, Ambala (Bahrat), v. 4, n. 2, p. 148-154, 2014. Disponível em: <http://www.ijidt.com/index.php/ijidt/article/view/4.2.9>. Acesso em: 1 out. 2017. 